\title{
Descentralização e federalismo: a política de saúde em novo contexto - lições do caso brasileiro
}

\author{
Decentralization and federalism: the health politics \\ in new context - lessons of the Brazilian case
}

Ana Luiza D'Ávila Viana 1

Luciana Dias de Lima 2

Roberta Gondim de Oliveira 3

\footnotetext{
1 Departamento de

Medicina Preventiva da Faculdade de Medicina, USP. Av. Dr. Arnaldo, 455/ 2 o andar, Cerqueira César 01246-903 São Paulo SP. analuivi@zaz.com.br

2 Departamento de Administração e Planejamento em Saúde. Escola Nacional de Saúde Pública, Fiocruz.

3 Ensino à Distância. Escola Nacional de Saúde Pública, Fundação Oswaldo Cruz.
}

\begin{abstract}
The article analyses the processes of decentralization and deconcentration, along with the new emergence of federalism, as global phenomena and meaningful tendencies in the reestructuring of the unitary and centralized State, built under the Napoleonic tradition. In the Brazilian case, in particular, the article identifies the different phases and problems that arose during the decentralization process and within the re-configuration of the federative pact since the 80 's, and evaluates the implications of this new order on the recent reform processes of the health policy. Furthermore, the article presents the conditions and limitations of healthsystem's decentralization, highlighting the risks to which it is submitted and taking into account unfavourable aspects of its context, characterised by federative conflicts and by the social and economic inequality inheritance.

Key words Health politics' decentralization, Intergovernmental relations, Federalism, Health system, SUS's Basic Operational Norms
\end{abstract}

Resumo O artigo analisa os processos de descentralização e desconcentração, aliados à nova emergência do federalismo, como fenômenos mundiais e tendências marcantes na reestruturação do Estado centralizado e unitário, erguido sob a tradição napoleônica; no caso brasileiro, em particular, identifica os períodos e problemas surgidos no processo de descentralização e na reconfiguração do pacto federativo, a partir dos anos 80, e avalia as implicações desta nova ordem nas reformas recentes da política de saúde. Por fim, apresenta os condicionantes e limites da descentralização setorial da saúde, evidenciando os riscos aos quais está submetida, considerando os aspectos contextuais desfavoráveis, caracterizados por conflitos de ordem federativa e pela herança de desigualdades socioeconômicas.

Palavras-chave Descentralização da política de saúde, Relações intergovernamentais, Federalismo, Sistema de saúde, Normas Operacionais Básicas do SUS 


\section{Descentralização e novo federalismo: tendências atuais}

A nova ordem dos Estados nacionais nos últimos vinte anos caracteriza-se pelos movimentos de descentralização e desconcentração, ao lado da multiplicidade de novas experiências e propostas federalistas e da propagação da criação de entidades federais no mundo ocidental.

Segundo Dente (1997), assiste-se a um progressivo desmantelamento do Estado centralizado e unitário, erigido sob a égide napoleônica, em que o tripé formado pelo parlamento, governo e burocracia ministerial não constitui mais a base sobre a qual se sustenta o Estado. Porém, como aponta o autor, isso não significa a emergência de um novo modelo facilmente reconhecível, para o qual possam convergir os diferentes sistemas político-institucionais.

Não é tarefa simples identificar as causas que concorrem para esse fenômeno, mas é possível agrupá-las segundo critérios distintos de interpretação:

a) sob a perspectiva econômica, as transformações impostas pela reestruturação do modo de produção e do funcionamento da economia, a partir de inovações tecnológicas e da globalização, ocasionaram profundas alterações na capacidade dos Estados nacionais de captarem recursos da esfera produtiva; por outro lado, impuseram um padrão de endividamento público crescente, o que acabou por ocasionar recorrentes déficits públicos. Esse fenômeno impôs a equação descentralização/federalismo como solução para governar a redução da despesa pública, como bem aponta Dente (1997). Segundo o autor, outrora, o aumento da despesa pública era a forma encontrada para resolver os conflitos político-territoriais. Atualmente, a redução da despesa pública tornou-se um meio de governar, visto que o federalismo tende a estreitar a correlação entre financiador e beneficiário.

b) sob a perspectiva política, são inúmeras as razões que impulsionaram a descentralização, destacando-se: 1) a transição do autoritarismo para democracia em muitos países do mundo ocidental, na década de 1970;2) a emergência de autoridades administrativas independentes, sem vínculos com o circuito tradicional parlamento/burocracia intermediado pelo governo, tais como agências reguladoras, bancos centrais independentes, o próprio mercado financeiro, os meios de comunicação de massa e as telecomunicações; 3 ) aniquilamento dos antigos ícones de identidade nacional com conteúdo polí- tico-ideológico - a exemplo dos fatos ocorridos a partir do esfacelamento dos países socialistas do Leste Europeu -, restando apenas o idioma como única característica coletiva de nacionalidade; e 4) permanentes desequilíbrios socioeconômicos entre regiões de um mesmo país.

c) sob a perspectiva do Estado, destaca-se a debilitação do Welfare State, visto que a busca pela eficiência e equilíbrio financeiro resultou em propostas de descentralização das atividades de regulação, provisão e financiamento de bens e serviços sociais.

Segundo Sharpe (1997), entretanto, a principal razão do movimento atual em prol da descentralização decorre da relevância do direito pessoal territorial (direito coletivo subnacional) sobre o direito à igualdade interpessoal. Sharpe (1997) alega que os dois dogmas básicos da democracia moderna, o direito dos cidadãos de desenvolverem plenamente sua capacidade - o direito à igualdade -, e o direito à identidade - $\mathrm{o}$ direito territorial -, mudaram de posição devido à crise dos WS. O primeiro satisfazia-se pelas ações do WS em prover os cidadãos de rendas compensatórias face às desigualdades criadas pelo mercado; o direito territorial, por sua vez, incorpora a eqüidade, não no sentido interpessoal, mas entre comunidades subnacionais. Foi justamente a incapacidade dos WSs de garantirem a plena ocupação que ocasionou a maior importância do direito territorial frente ao direito interpessoal. Esse processo origina-se, primeiramente, do esgotamento das formas anteriores de representação de interesses, baseadas no neocorporativismo, em que a grande empresa, a burocracia e o sindicato eram os atores dominantes das decisões políticas; segundo, pelo processo de territorialização da policy making (territorialização da política), explicado pela acelerada expansão da urbanização, pelo recrudescimento de governos subnacionais, pelo surgimento do fenômeno do meso-livello ou meso-government - seguido da emergência de novos atores territoriais - e, por fim, pelos questionamentos ao WS como provedor por excelência do direito à igualdade.

Segundo o autor, a tríade composta pela modernização, industrialização e democratização ou o reconhecimento da relação de igualdade entre modernização e centralização - estimulou, como resposta, a formação de anticorpos, criando-lhe um movimento contrário, de negação, pela necessidade de afirmação e sobrevivência de culturas regionais, dos direitos das minorias e de sua maior participação (não mais tão-somente pela via da democracia representativa). 
Em âmbito mundial, o tripé formado pelo governo central, parlamento e burocracia ministerial foi substituído por novos elementos onde se destacam os governos subnacionais, as novas autoridades administrativas, o mercado e o setor terciário -, o que caracteriza acentuadamente a transformação atual do Estado.

Segundo Dente (1997), o desgaste do poder dos Estados nacionais lhes confere novas aparências e o processo de erosão observa-se a partir de três ângulos: para cima, a favor da dimensão internacional; para baixo, através da descentralização; e, por fim, lateralmente, a favor das autoridades administrativas independentes.

Dessa forma, o federalismo reemergiu nesse cenário, inserindo-se na tendência descentralizante, defrontando-se hoje, como bem afirma Sharpe (1997), com novos problemas: ao invés de ser a solução para entidades diferentes, que buscam a união entre si - o que o autor denomina de "velho federalismo" -, o atual, ao contrário, vislumbra um objetivo oposto, o de dividir o que era unitário, constituindo-se assim um "novo federalismo".

\section{Qual federalismo?}

As discussões sobre federalismo apóiam-se numa diversidade de estudos de diferentes enfoques (econômico, histórico e jurídico), que tendem, às vezes, a separar questões políticas das econômico-financeiras (Kugelmas, 1999 e Souza, 2001). Os autores citados ponderam que análises circunscritas a um determinado campo carecem, quase sempre, de base teórica, e, por isto mesmo, não servem à análise de fenômenos que extrapolam seu próprio enfoque. Por esta razão, coexistem análises distintas e mesmo contraditórias acerca do funcionamento do federalismo.

Para Souza (1999), boa parte da literatura sobre o tema tem sido, em geral, normativa ou incompleta. Em contrapartida, a ciência políti$\mathrm{ca}$, em especial a norte-americana, adotou princípios que, apesar de discutirem alguns aspectos específicos do federalismo, forneceram bases teóricas para a análise de questões mais amplas que envolvem uma federação, avançando no que se refere aos estudos comparativos (Souza, 1999). Contudo, esse enfoque mais geral não tem se mostrado suficiente para analisar as diferenças nos arranjos federativos dentro de uma mesma federação. No esforço de superar essas limitações é que Souza lança mão das formulações de Burgess, pois este concebe o federalis- mo como conceito de valor que informa a federação: "a lógica das federações é o federalismo, que é a percepção ideológica do que deve acontecer após a federalização". O federalismo, assim entendido, investiga as motivações (padrões de interesses), em contextos econômicos, políticos e socioculturais específicos, que levam ao desenho de cada federação. Essa distinção é fundamental ao estudo dos diferentes arranjos no federalismo.

Foram criados diversos tipos de federalismo, o que torna impossível mencionar um único modelo de federalismo. As relações entre governo central/unidades periféricas têm sido tratadas e exemplificadas por meio de três modelos de federalismo - dual, cooperativo e competitivo -, recorrentes nas análises sobre o tema. Porém, como bem aponta a literatura recente sobre esta temática específica, a instabilidade dos arranjos federativos e dos processos de centralização e descentralização indica a necessidade de se distinguir Federação de federalismo, tendo em vista a variedade de princípios federais dentro de cada federação, em virtude de determinadas circunstâncias históricas, variando de acordo com a dinâmica da economia política, dos partidos e da cultura política (Souza, 2001). Em suma, a variável independente dos modelos federativos é a dinâmica da intervenção pública.

Dessa forma, a discussão abstrata dos tipos de federalismo não contribui efetivamente com as análises sobre políticas públicas, pois é rara a existência de um modelo único e permanente de relação centro/periferia. É fundamental que se compreenda a dinâmica da intervenção pública e que se identifiquem as variáveis que interferem nesse processo, em detrimento da mera descrição de modelos ideais e abstratos.

\section{Políticas públicas em um contexto de recriação de flexibilidade institucional}

Para a análise de políticas públicas (policy ma$k i n g$ ), é fundamental que se entenda a atual dinâmica institucional da intervenção pública, caracterizada por grande flexibilidade, mais presente no modelo federalista do que no modelo do Estado unitário, e base das atuais reformas dos Estados nacionais.

A flexibilidade institucional implica a busca pela cooperação intergovernamental para alcançar fins comuns, tanto em matéria econômica como social e cultural, através de programas e de financiamentos conjuntos. Para Croi- 
sat (1995), entretanto, essa busca de cooperação é característica do federalismo cooperativo, fruto da evolução do federalismo contemporâneo, que emerge a partir do New Deal, na década de 1930, nos Estados Unidos, como forma de atacar a crise econômica dos anos 20.

Esse modelo flexível forma-se a partir de medidas legislativas e reguladoras em todos os níveis de governo, no interior da estrutura constitucional, em que se aplica uma concepção intergovernamental de políticas públicas.

Segundo Dente (1997), a implantação de políticas públicas em um cenário federalista caracterizado pela flexibilidade institucional é acompanhada pela emergência de estruturas dedicadas à construção da relação centro/periferia, pela pluralidade de centros de decisão autônomos e interdependentes, pelo reforço de burocracias eficientes e profissionais nos diferentes níveis de governo e, finalmente, pela figura dos managers intergovernamentais.

A realidade da política pública no Estado contemporâneo é complexa, caracterizada por intensas negociações, conflitos e cooperação, além da participação de diferentes atores e níveis de governo, dotados de variados tipos de legitimação, empregando recursos diversos, o que justifica a permanente necessidade de criação de estruturas dedicadas à relação centro/periferia, como instrumentos da diplomacia intergovernamental, sem o que dificilmente implantar-se-iam políticas e programas públicos com algum grau de eficiência. Neste caso, vale registrar a apropriada citação de Dente (1997): "governar em um contexto federal é também governar com paciência”.

\section{Períodos e problemas da descentralização e do federalismo brasileiro}

No Brasil, segundo Souza (2001), o federalismo apresenta-se como uma instituição moderadora das profundas disparidades regionais, e suas características atuais conformam uma federação que constrange o centro e redireciona o papel dos governos subnacionais na provisão dos serviços sociais, porém, com grande diversidade de respostas, em razão das profundas disparidades inter- e intra-regionais.

As diversas análises realizadas sobre o tema das relações intergovernamentais - sejam as que priorizam a distribuição de recursos ou aquelas que relevam as relações político-administrati- vas - são convergentes, visto que identificam três grandes períodos marcados por uma dinâmica de tensão e distensão de controles políticos e fiscais, como assinalam Kugelmas \& Sola (2000): um primeiro, de alto centralismo, característico da fase do regime autoritário; outro, orientado para a descentralização e formação de um novo modelo federalista (anos 80); e um terceiro, indefinido quanto ao modelo de federação, mas com traços de recentralização e ausência marcante de mecanismos cooperativos, denominado de federalismo predatório, vigente nos anos 90 .

A identificação destes três períodos distintos não descarta a existência de alguns aspectos de continuidade entre eles. No movimento de oscilação entre centralização e descentralização no federalismo brasileiro há, em certa medida, um continuum institucional, visto que aspectos da dinâmica institucional que antecedem às novas orientações não são de todo anulados quando esta entra em vigor. Esse princípio pode ser especialmente útil na observação do caso brasileiro, em que convergem "aspectos recentralizadores e descentralizadores” (Kugelmas \& Sola, 2000).

Segundo Abrucio (1998), o modelo "unionista-autoritário", que vigorou como forma de relação intergovernamental no período do regime militar, firmava-se sobre três pilares: o financeiro, o administrativo e o político. A centralização de receitas pelo executivo federal, a uniformização administrativa nas três esferas de governo e o controle das eleições para governadores asseguravam a predominância da União sobre os demais entes federados.

A transição para um novo modelo de relação intergovernamental tem início na segunda metade da década de 1970, consolidando-se com as eleições diretas para os governos estaduais em 1982 - restauradoras da democracia -, que concorreram para a definição de um novo modelo, denominado por Abrucio como "federalismo estadualista”, em razão do fortalecimento do poder dos governadores ao longo da década de 1980, assentado sobre a coincidência temporal entre as crises do Estado desenvolvimentista e a do regime militar; aliado ao contínuo crescimento financeiro das unidades subnacionais, ao papel dos governadores na transição democrática, à importância das eleições estaduais para o sistema político e à crise do presidencialismo brasileiro durante a década de 1980 e começo da de 1990.

Como resultado dessa crise, o autor cita o enfraquecimento do executivo federal e da Pre- 
sidência da República perante o Congresso Nacional, bem como da União perante os Estados: a crise financeira do governo federal no início da década de 1980, a conquista dos governos estaduais pela oposição, o papel dos governadores na transição e, por fim, as regras estabelecidas pela Constituição de 1988 destruíram o antigo modelo de federalismo (Abrucio, 1998). Nesse período, a noção de democracia vincula-se estreitamente ao conceito de descentralização: ao longo do processo de elaboração do novo texto constitucional, houve pressão por parte de muitos grupos, especialmente aquele formado por prefeitos e governadores, que lideravam o movimento em prol da descentralização financeira.

Assinale-se que, durante a década de 1980, as unidades subnacionais aumentaram sua participação nas receitas nacionais, a partir da emenda Passos Porto, em 1983, consolidada, posteriormente, na Constituição Federal de 1988. Entretanto, como ressalta Abrucio, a descentralização no Brasil ocorreu sob um padrão perverso de políticas públicas, pois nem a União conseguiu governar esse processo, nem os estados mudaram seu comportamento na elaboração da ação pública, visto que se mantiveram a politização da administração pública estadual, a dependência do sistema eleitoral ao governo estadual, a ausência de contrapesos regionais, a baixa visibilidade política e a neutralização dos órgãos fiscalizadores estaduais.

Assim, o poder dos governadores alicerça-se sobre uma relação de lealdade (que deve vigorar nas eleições), vinculada à distribuição de cargos do executivo estadual e à montagem de uma estrutura clientelista junto aos prefeitos e líderes locais.

O estudo recente de Couto e Silva (1998) sobre o processo de mudança nas relações intergovernamentais, considerando-se os aspectos fiscais e financeiros, revela que a tendência à descentralização, presente na Constituição de 1988 - autonomia dos governos estaduais no campo fiscal; discriminação das receitas tributárias de cada nível de governo; aumento da participação dos governos subnacionais na carga tributária e constituição da seguridade social -, foi revertida na década de 1990, em virtude da apropriação, pelo Orçamento Geral da União, dos recursos previstos para o financiamento da Seguridade e dos desequilíbrios financeiros dos governos subnacionais. Ressalta-se que as relações intergovernamentais se estabelecem em torno das transferências tributárias; das transferências não-tributárias; e dos empréstimos e financiamentos.
Segundo o referido estudo, a incapacidade de manutenção do processo de descentralização decorre da fragilidade da base de sustentação fiscal dos estados. A frustração da descentralização é indissociável do ajuste fiscal: no Brasil, este processo se dará tanto pela recentralização fiscal propiciada pelo crescimento da participação das contribuições sociais na receita federal - e a decorrente frustração das políticas sociais descentralizadoras, como saúde e educação -, quanto pelas soluções encaminhadas para a superação da crise financeira dos governos subnacionais (Couto e Silva, 1998).

Assim, frustra-se a proposta de descentralização, pelas razões abaixo mencionadas:

a) a previsão de aumento da participação das instâncias subnacionais nos fundos de participação não se efetivou, decaindo, entre 1988 e 1996 , de $21 \%$ para $15 \%$ a sua participação na receita tributária da União, uma vez que os tributos partilhados - Imposto de Renda (IR) e Imposto sobre Produtos Industrializados (IPI) - não acompanharam a evolução desta receita; b) os estados perderam autonomia, em razão dos seus níveis crescentes de endividamento; c) os recursos da seguridade foram contingenciados (primeiro, no período inflacionário, através dos atrasos na liberação; segundo, após a estabilização, pela criação do Fundo Social de Emergência e posterior Fundo de Estabilização Fiscal), tornando a seguridade uma variável de ajuste do processo de estabilização.

Em suma, o processo de territorialização das políticas públicas, as mudanças no perfil urbano brasileiro, o incremento de recursos para as instâncias subnacionais e a redemocratização foram os fatores que desencadearam um novo ciclo descentralizador, a partir do início dos anos 80, culminando na Constituição de 1988; nos anos 90, assiste-se a uma tendência recentralizadora, dos pontos de vista fiscal e político, e a uma fase de transição para um novo pacto federativo.

Esta indefinição, ao lado da recentralização de recursos, da perduração de formas arcaicas no exercício da política e na administração, da ausência de ações coordenadas nos três níveis de governo - pela inexistência de um regime de atribuições explícitas e de um acordo de competências - e, sobretudo, pelo não-enfrentamento da reforma do Estado dentro de uma perspectiva federalista, resulta em padrões muito diferenciados de políticas setoriais.

As análises recentes sobre o processo de descentralização, a partir de exemplos setoriais, demonstram a ausência de avaliações das diferen- 
tes capacidades financeira e administrativa dos municípios para suportar e absorver novas atribuições gestoras. Não há, portanto, um modelo único de descentralização, pois as inumeráveis desigualdades regionais e locais geram resultados muito diferenciados.

\section{A política de saúde em novo contexto: indução federal à descentralização e autonomia local}

Há mais de duas décadas, o Brasil vive uma extraordinária experiência de reformas e redefinição do perfil do seu sistema de saúde. Nos anos 80 , as mudanças no sistema público de saúde culminaram com a emergência do Sistema Único de Saúde (SUS), como tópico integrante da própria Constituição Federal de 1988.

$\mathrm{Na}$ década seguinte, reformularam-se os papéis e funções dos entes governamentais na oferta de serviços, na gerência de unidades e na gestão do sistema de saúde. Adotaram-se novos critérios de alocação e transferência de recursos e criaram-se novas instâncias colegiadas de negociação, integração e decisão, envolvendo a participação dos gestores, prestadores, profissionais de saúde e usuários, através da formação dos Conselhos de Saúde nos diferentes níveis de governo e das Comissões Intergestores Tripartite e Bipartite, de caráter mais especializado e restrito, envolvendo a participação dos gestores da política nos planos federal, estadual e municipal.

Assinale-se que a emergência do SUS devese, basicamente, a dois fatores: por um lado, o intenso processo de sucessivas mudanças na política de saúde, iniciado ainda na década de 1970 e intensificado na década seguinte, através das AIS e SUDS (mais especificamente a partir de 1983); e, por outro, ao processo de territorialização das políticas, impulsionado pelo movimento de urbanização típica dos anos 70 , que induziu os municípios a assumirem, de forma experimental, uma série de responsabilidades e atribuições no campo das políticas de saúde.

O SUS conforma o novo modelo público de prestação de serviços e ações de saúde em âmbito nacional, incorporando novos instrumentos gerenciais, técnicos e de democratização da gestão. Em sua concepção original, visa integrar os subsistemas de saúde pública e de assistência previdenciária - os ramos da medicina preventiva e curativa -, bem como os serviços públicos e privados, em regime de contrato ou convênio, num sistema único e nacional, de acesso univer- sal e igualitário, organizado de forma regionalizada e hierarquizada, sob comando único em cada nível de governo, segundo as diretrizes da descentralização administrativa e operacional, do atendimento integral à saúde e da participação da comunidade visando ao controle social.

Este modelo, portanto, extremamente complexo, envolve múltiplas variáveis e só se concretiza através do estabelecimento de relações interinstitucionais, interníveis de governo e interserviços. A descentralização associada à diretriz da gestão única resulta em três arranjos formais para o sistema de saúde: os sistemas municipais, estaduais e o nacional. No entanto, a integralidade e a hierarquização induzem à formação de outros subsistemas, como conseqüência da negociação intergestores. Admitindo múltiplos partícipes, estes arranjos são fruto de acordos políticos e do desenvolvimento de instrumentos técnico-operacionais necessários à integração e manutenção da unicidade do sistema.

A implementação do SUS inicia-se nos primeiros anos da década de 1990, após a promulgação da Lei Orgânica da Saúde, e de várias normas e portarias emitidas pelo Ministério da Saúde - as Normas Operacionais Básicas (NOBs) - como instrumentos de regulamentação do sistema. Sublinhe-se que as referidas normas definem a forma de transferência de recursos interinstâncias de governo e as modalidades de pagamento dos serviços de saúde, além de instruírem o processo de descentralização e de construção de uma rede de serviços capaz de operar com racionalidade sistêmica.

É natural que se indague como é possível a convivência pacífica de uma política cujo perfil incorpora uma proposta fortemente descentralizadora e, ao mesmo tempo, exige um pacto federativo mais cooperativo, como o SUS, com relações intergovernamentais marcadas por incessantes conflitos e embates sobre recursos, centralização excessiva, fragmentação institucional, frágil capacidade reguladora e inexpressiva tradição participativa da sociedade.

Não se pode assegurar que as políticas de descentralização no setor da saúde desencadeiem um círculo virtuoso, pois se sabe que as partilhas regionais e locais giram em torno de recursos reconhecidamente escassos. Dessa forma, mantêm-se as desigualdades de representação e de poder, o que pode intensificar o jogo predatório nas relações entre entes da federação nas políticas sociais. Portanto, a federação não pode prescindir de poderosos recursos reguladores, que devem contemplar estratégias, instru- 
mentos e mecanismos claros de accountability.

Resta saber se as variáveis internas setoriais como as regulações federais sobre a implantação do SUS colocadas em prática no decorrer dos anos 90 (NOBs 91, 93 e 96) - e as variáveis externas extra-setoriais, como as policy making de cada estado e/ou município, cumpriram um papel neutralizador das influências de ordem macro ou aprofundaram essas mesmas características.

As análises sobre o processo recente de descentralização apontam, na área social e, em específico, na saúde, a tendência de as variáveis microinstitucionais (poderes locais) terem respondido de forma mais direta pelo (in)sucesso de determinadas políticas, evidenciando um grau de autonomia da gestão local.

As respostas às pressões por maior participação dos municípios na área social e em específico na área de saúde, bem como a alta heterogeneidade socioeconômica, política, cultural, demográfica e epidemiológica, propiciaram a formação de modelos singulares de saúde, tanto regionais como locais. Esses modelos são identificados por características particulares, uma vez que as configurações locais dependem de inúmeras variáveis. Neste caso, destacam-se: as formas anteriores ou pretéritas de gestão e organização dos serviços; os arranjos políticos e as formas de expressão dos interesses no plano regional; o tipo de relacionamento estabelecido entre as esferas de poder - executivo, legislativo e judiciário; o grau de associonismo e de capital social criados e desenvolvidos; e, por fim, os perfis de financiamento e gasto local em saúde.

Conseqüentemente, o sucesso de determinadas políticas setoriais em espaços e/ou territórios geográficos específicos deve ser atribuído antes a contextos sociais e culturais mais amplos do que a modelos institucionais prévios, como já foi assinalado por Kugelmas \& Sola.

Por certo, pode-se assegurar que a política de saúde, através de inúmeros instrumentos, procurou superar contradições e conflitos inerentes às relações intergovernamentais geradas em um quadro de federalismo predatório.

\section{Elementos constitutivos da regulação do processo de descentralização}

O processo de descentralização e de construção de um poder gestor municipal, integrado de forma sistêmica, sofreu numerosos percalços por conta da evolução das práticas e de instituições federativas nos anos mais recentes, e dos cons- trangimentos criados pelas demandas da política econômica.

Contudo, a política descentralizadora na área da saúde contou, no Brasil, com uma forte indução estratégica de centro, através da formulação e implementação de instrumentos reguladores próprios - as Normas Operacionais Básicas (NOBs) de 1991/93 e 96 - e a Norma Operacional da Assistência (NOAS), de 2001. As NOBs, todavia, não expressam meramente estratégias indutivas ou constrangedoras da descentralização; ao contrário, configuram outros espaços de negociação e de pactuação de interesses na área da saúde, originando novos ordenamentos, além da emergência e do fortalecimento de novos atores, através da incorporação de inúmeros centros de poder na arena decisória da política.

É através deste processo de crescente democratização e politização da descentralização que a política ganha definitiva estabilidade, de forma a neutralizar coalizões anti-reformas e aprofundar instrumentos reguladores com alto grau de consenso.

Por outro lado, as NOBs formam um conjunto contínuo, posto que, de certa forma, cada Norma criou uma série de contradições que passaram a ser resolvidas pela Norma subseqüente, numa tentativa ascendente de adequar o processo de descentralização setorial à racionalidade sistêmica, aos modelos de atenção à saúde e ao financiamento (federativo e dos prestadores privados). São justamente as contradições existentes nesta tríade que conformam, tensionam e desatualizam cada Norma Operacional Básica em operação, como pode ser visto resumidamente no quadro 1.

O sistema idealizado pelo SUS pressupõe a coordenação de ações entre diferentes instâncias governamentais, reordenadas de acordo com uma proposta de regionalização que vise à otimização dos recursos disponíveis. As relações intergovernamentais - lato sensu, compreendendo o financiamento, a administração e a política - devem ser cooperativas e capazes de solucionar conflitos, pois o acesso aos serviços subordina-se a estes mesmos acordos, tendo em vista a desigualdade da sua distribuição no território nacional.

Esse apelo à construção de um sistema ao lado de uma estratégia visando compensar as diferenças locais, de forma a propiciar uma descentralização menos heterogênea, orientou a formulação e implementação de alguns instrumentos-chave, incluídos nas NOBs (principalmente as NOBs 93 e 96), tais como: 
Quadro 1

Elementos constitutivos da regulação do processo de descentralização: racionalidade sistêmica, financiamento federal e modelos de atenção à saúde. NOBs 91, 93 e 96 e NOAS 2001

\begin{tabular}{|c|c|c|c|}
\hline Normas & Racionalidade Sistêmica & Financiamento Federal & $\begin{array}{l}\text { Modelos } \\
\text { de Atenção }\end{array}$ \\
\hline $\mathrm{NOB} / 91$ & Ausente & Repasse direto ao prestador segundo produção aprovada & Ausente \\
\hline $\mathrm{NOB} / 93$ & $\begin{array}{l}\text { Fraca: vinculada às iniciativas } \\
\text { e negociações municipais isoladas }\end{array}$ & $\begin{array}{l}\text { Repasse direto ao prestador segundo produção aprovada } \\
\text { Transferência "fundo a fundo" segundo montante } \\
\text { definido no teto financeiro }\end{array}$ & Ausente \\
\hline $\mathrm{NOB} / 96$ & $\begin{array}{l}\text { Moderada : vinculada às iniciativas } \\
\text { e negociações intermunicipais, } \\
\text { com participação e intermediação } \\
\text { da instância estadual (PPI) }\end{array}$ & $\begin{array}{l}\text { Repasse direto ao prestador segundo produção aprovada } \\
\text { Transferência "fundo a fundo" segundo montante } \\
\text { definido no teto financeiro } \\
\text { Transferência "fundo a fundo" segundo valor per capita } \\
\text { Transferência "fundo a fundo" segundo critérios definidos } \\
\text { por programas específicos }\end{array}$ & PACS/PSF \\
\hline NOAS/2001 & $\begin{array}{l}\text { Forte: vinculada às definições } \\
\text { do conjunto de ações e serviços } \\
\text { a serem contemplados nos módulos } \\
\text { assistenciais pelo nível federal } \\
\text { e às iniciativas e negociações } \\
\text { intermunicipais sob coordenação da } \\
\text { instância estadual (PPI, PDR e PDI) }\end{array}$ & $\begin{array}{l}\text { Repasse direto ao prestador segundo produção aprovada } \\
\text { Transferência "fundo a fundo" segundo montante } \\
\text { definido no teto financeiro } \\
\text { Transferência "fundo a fundo"segundo valor per capita } \\
\text { Transferência "fundo a fundo" segundo critérios definidos } \\
\text { por programas específicos } \\
\text { Transferência "fundo a fundo" segundo valor per capita } \\
\text { e definição de referências intermunicipais } \\
\text { Definição das responsabilidades mínimas para a atenção básica }\end{array}$ & $\mathrm{PACS} / \mathrm{PSF}$ \\
\hline
\end{tabular}

Fonte: Elaboração própria das autoras

a) a criação e ampliação das funções dos Conselhos de Saúde e das Comissões Intergestores Tripartite e Bipartite (CIT e CIB), com a presença de representantes dos Conselhos de Secretários Estaduais e Municipais (Conass e Conasems/Cosems); b) as transferências automáticas per capita - PAB fixo e variável;

c) os incentivos ao desenvolvimento e à assunção de capacidades gestoras (aprendizado institucional), vinculados ao processo de habilitação, cujas modalidades estão previstas nas NOBs 93 e 96, para municípios e estados.

A seguir, verificar-se-ão as influências exercidas por cada um dos instrumentos acima identificados sobre o processo de descentralização.

\section{Tendências da descentralização em saúde: descentralização (municipal) de equipamentos ao lado de gestão compartilhada (estados/municípios)}

As Comissões Intergestoras, particularmente as CIBs, foram instrumentos importantes para a construção da intergestão e essenciais à formação dos sistemas intermunicipais; instituíram-se como foros permanentes de negociação, planejamento e decisão intergovernamental. Além disso, ao se adequarem as normas nacionais às condições específicas de cada Estado, preservou-se a autonomia dos demais entes governamentais no processo de descentralização.

A última NOB editada na década de 1990, a NOB/96, instituiu que os municípios habilitados na condição de gestão plena assumissem a responsabilidade sobre o conjunto de ações e serviços no âmbito de seu território, à revelia das complexidades e idiossincrasias locais, pelo menos no que se refere aos aspectos relevantes da iniciativa de comando sobre o conjunto do sistema (contrato com prestadores, cadastramento, programação orçamentária de unidades ambulatoriais, autorização de internações hospitalares, pagamento, controle, avaliação e auditoria).

No entanto, a decisão sobre a partilha de gestão entre estado e municípios foi atribuída às CIBs. É preciso enfatizar que a partilha de gestão, embora associada mais intensamente à $\mathrm{NOB} / 96$, já estava presente na NOB/93, e pode 
ser observada nos diferentes graus de responsabilidades e funções gestoras assumidas pelos municípios habilitados na condição de gestão semiplena. Mesmo os municípios habilitados em gestão plena da atenção básica na NOB/96, por decisão das CIBs, podem assumir responsabilidades mais complexas no sistema de saúde local, não-relacionadas exclusivamente à atenção básica. Essa medida possibilitou a geração dos mais variados tipos ou modelos de gestão e partilha entre as diversas unidades da federação. Há, portanto, graus variados de poder de interferência do gestor municipal em seu território, nem sempre diretamente associado à condição de habilitação ou gestão prevista na NOB/96.

Estes arranjos - relativamente descentralizantes, mais ou menos organizativos para os sistemas - refletem não só a capacidade gestora, o grau de qualificação gerencial das Secretarias Estaduais de Saúde (SES) e Secretarias Municipais de Saúde (SMS) e as diferentes condições de gestão assumidas por estados e municípios, como também o grau de amadurecimento das discussões e as particularidades locais e regionais do relacionamento entre as instâncias de governo.

Os distintos modelos de gestão associados à capacidade instalada ambulatorial e hospitalar, no período de 1998 a 2000, estão apresentados, respectivamente, nas figuras 1 e 2 a seguir, e de- vem ser analisados à luz do processo de habilitação na NOB/96.

A maioria dos municípios foi habilitada na NOB/96, em 1998. Em dezembro daquele mesmo ano, segundo dados do Ministério da Saúde (MS), 4.597 municípios estavam habilitados na condição de gestão plena da atenção básica $(83,5 \%)$ e 452 na condição de gestão plena do sistema municipal $(8,2 \%)$. Em dezembro de 2000, o percentual de municípios habilitados em alguma condição de gestão na NOB/96 chega a $99 \%$, sendo 523 municípios habilitados na condição de gestão plena $(9,5 \%)$.

Com relação aos estados, o processo de habilitação na NOB/96 foi mais gradativo, sendo que em dezembro de 2000, quatro estados estavam habilitados em gestão plena do sistema estadual (Alagoas, Distrito Federal, Paraná e Santa Catarina) e quatro em gestão avançada do sistema estadual (Bahia, São Paulo, Minas Gerais e Rio Grande do Sul).

As figuras 1 e 2 apontam para um processo de descentralização da gestão com forte participação da instância estadual, mesmo num contexto de indução acentuada à descentralização de funções e recursos para os municípios. Notase que $22 \%$ das unidades ambulatoriais cadastradas no SUS em dezembro de 2000 estavam sob gestão estadual exclusiva $(7,5 \%)$ ou partilhada $(14,1 \%)$. Naquela mesma época, $61 \%$ das uni-

Figura 1

Evolução da capacidade instalada ambulatorial por tipo de gestão ambulatorial Brasil - dezembro de 1998 a dezembro de 2000

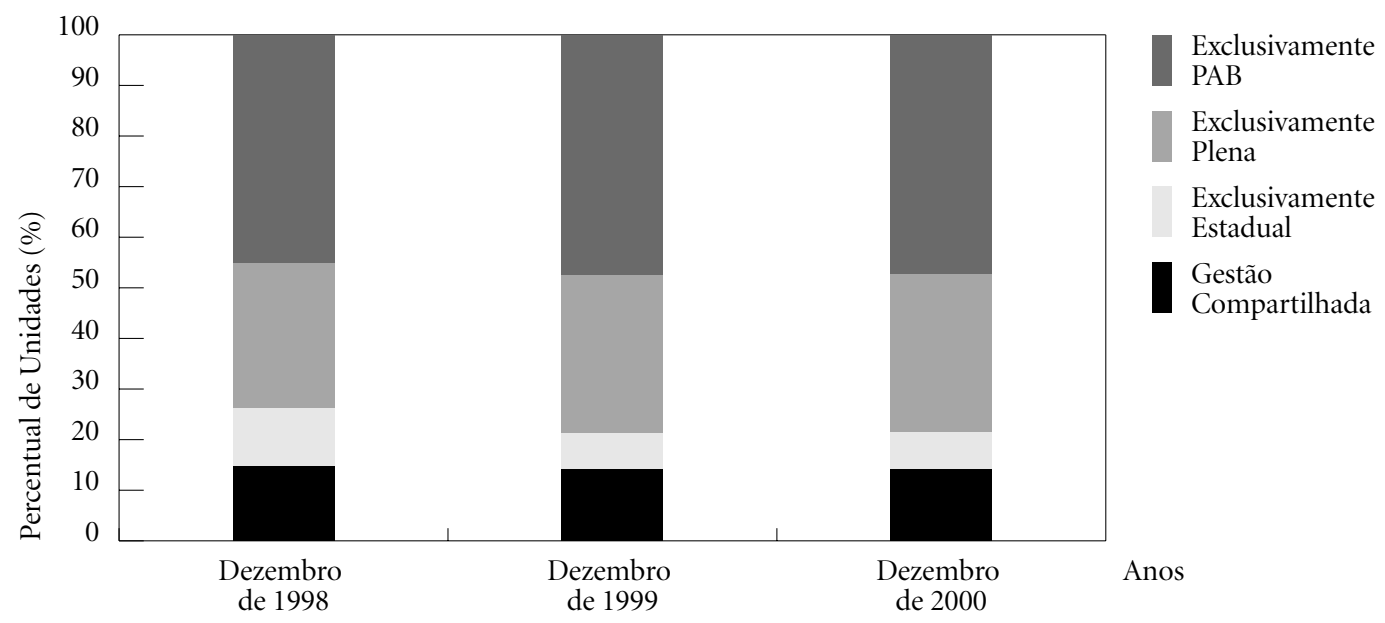


Figura 2

Evolução da capacidade instalada hospitalar por tipo de gestão

Brasil - dezembro de 1998 a dezembro de 2000

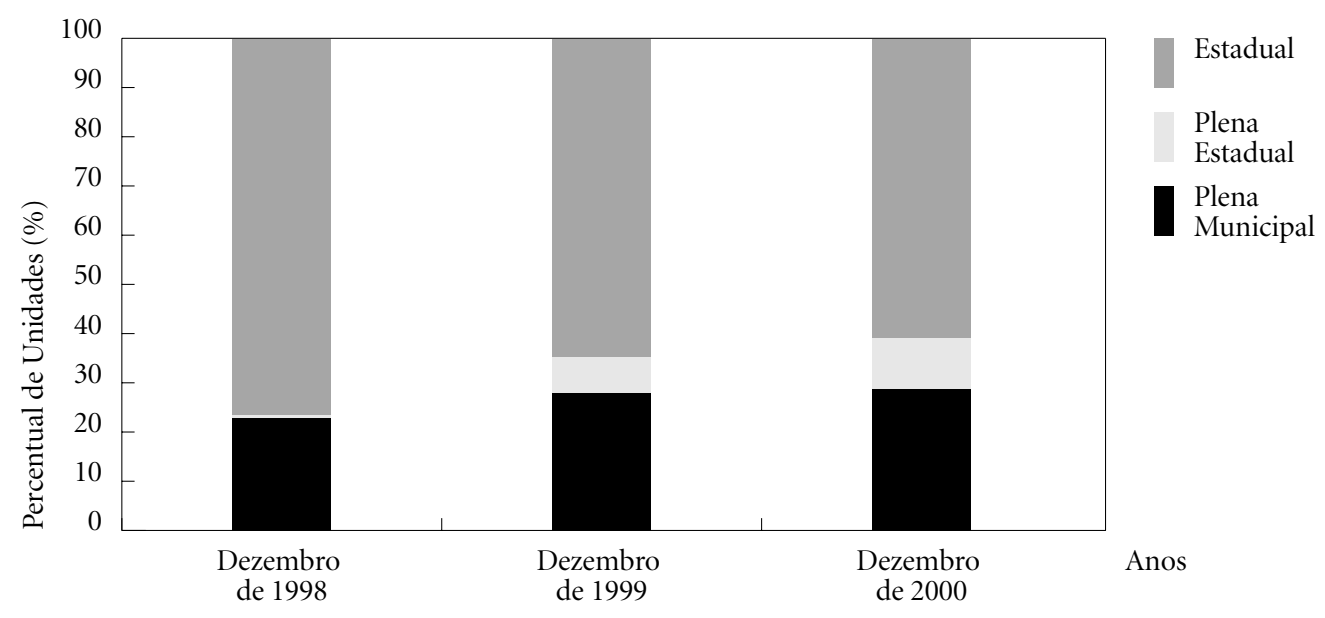

Fonte: DATASUS/MS

dades hospitalares cadastradas estavam sob gestão estadual.

Analisando-se a partilha de gestão das unidades ambulatoriais e hospitalares nas diversas regiões brasileiras, é possível evidenciar com maior clareza os diferentes graus de participação da instância estadual na gestão dos sistemas de saúde (figuras 3 e 4), sendo esta mais expressiva nas regiões Sudeste, Sul e Centro-Oeste do país.

Vale ressaltar que a tendência observada em relação ao processo de descentralização da gestão do sistema de saúde não parece coincidir com o processo de descentralização e municipalização da gerência das unidades de saúde.

Como apontam as figuras 5 e 6, a importância da oferta de serviços de natureza pública e municipal cresce significativamente, em detrimento da oferta de serviços privados e federais (municipalização de unidades), no período de 1998 a 2000.

Em dezembro de 1998, as unidades ambulatoriais municipais representavam $65 \%$ do total de unidades cadastradas no SUS, subindo para $71 \%$ em dezembro de 2000 (Figura 5). O mesmo não se observa em relação às unidades ambulatorias estaduais, que representam cerca de $4 \%$ das unidades cadastradas em dezembro de 1998 e 2000. A figura 6 demonstra que, embora a importância da participação das unidades hospitalares municipais tenha também aumentado no período, não parece ter sido tão significativa ( $22 \%$ para $24 \%$ ), permanecendo as unidades privadas contratadas e filantrópicas como as principais provedoras do SUS na área hospitalar (62,7\% das unidades cadastradas em dezembro de 2000).

O perfil da capacidade instalada ambulatorial e hospitalar, segundo sua natureza jurídica, também se apresenta bastante variado nas diferentes regiões do país (Figuras 7 e 8). A importância da oferta de serviços ambulatoriais de naturezas pública e municipal é particularmente expressiva nas regiões Sudeste, Norte e Nordeste, crescendo a importância do setor privado nas regiões Sul e Centro-Oeste . Já em relação às unidades hospitalares, observa-se a maior participação de serviços públicos municipais nas regiões Nordeste, Norte e Centro-Oeste, sendo a oferta de serviços públicos estaduais bastante expressiva, tanto na área ambulatorial como hospitalar, na região Norte.

As transferências automáticas ("fundo a fundo") propiciaram, por um lado, maior autonomia do gestor municipal, e, por outro, descentralizaram os recursos da saúde, estendendo-os a milhares de municípios que, até então, não haviam sido contemplados com repasses federais. Segundo dados do MS, em dezembro de 2000, 5.450 municípios (99\%) e 8 estados já re- 
Figura 3

Capacidade instalada ambulatorial por região por tipo de gestão

dezembro de 2000

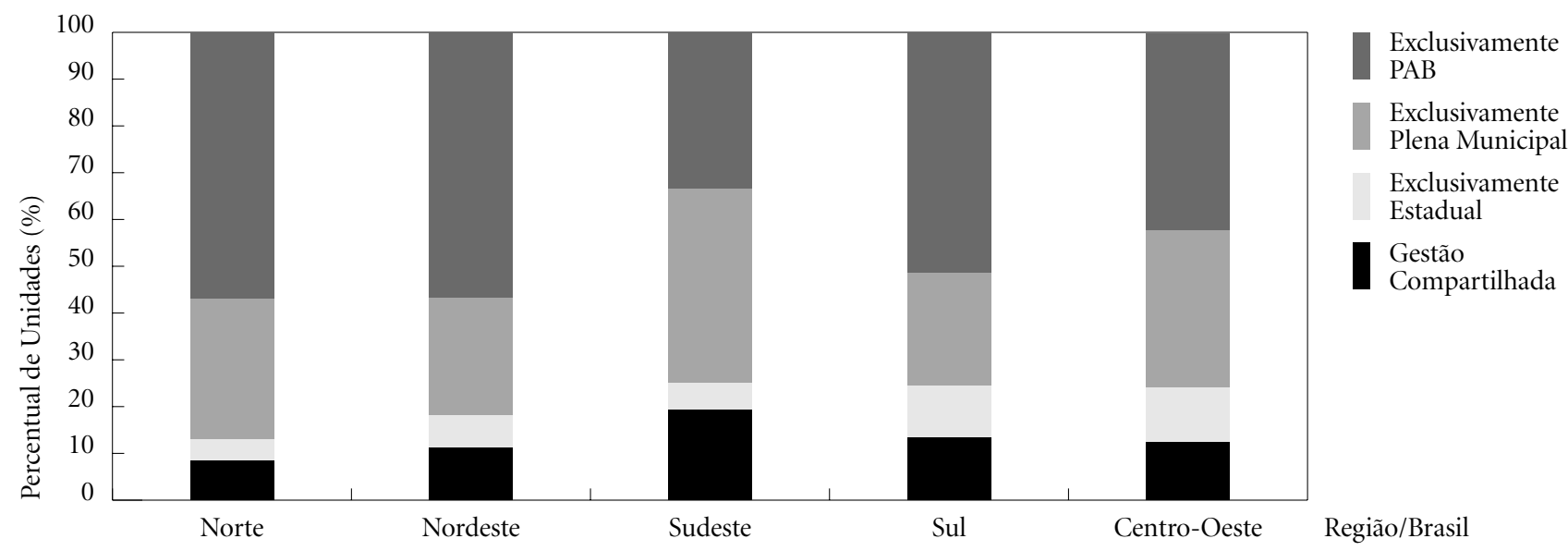

Figura 4

Capacidade instalada hospitalar por região por tipo de gestão

dezembro de 2000

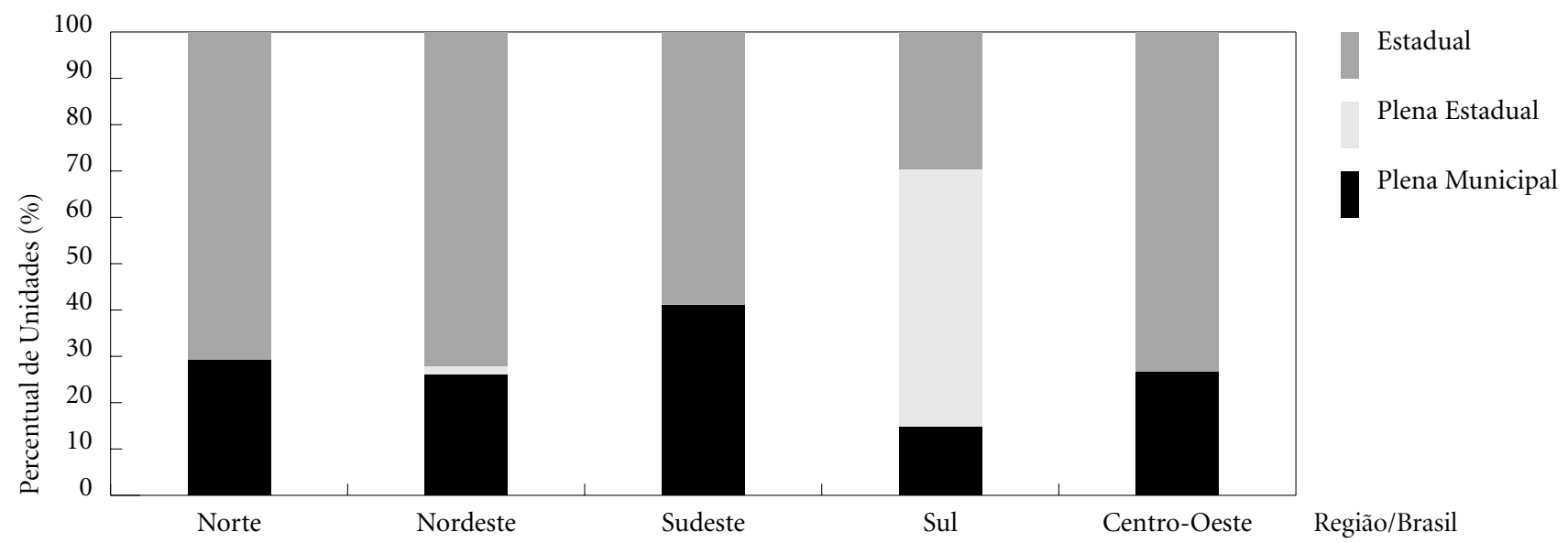

Fonte: DATASUS/MS 
Figura 5

Evolução da capacidade instalada ambulatorial por tipo de prestador Brasil - dezembro de 1998 a dezembro de 2000

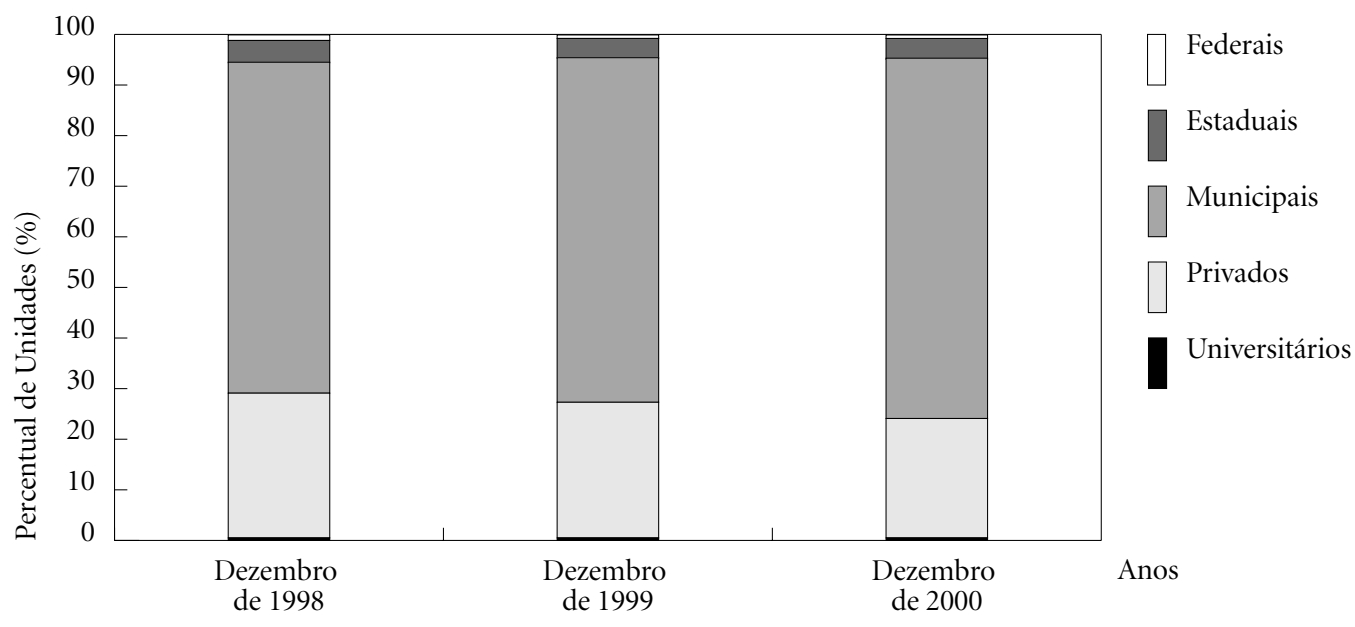

\section{Figura 6}

Evolução da capacidade instalada hospitalar por tipo de prestador Brasil - dezembro de 1998 a dezembro de 2000

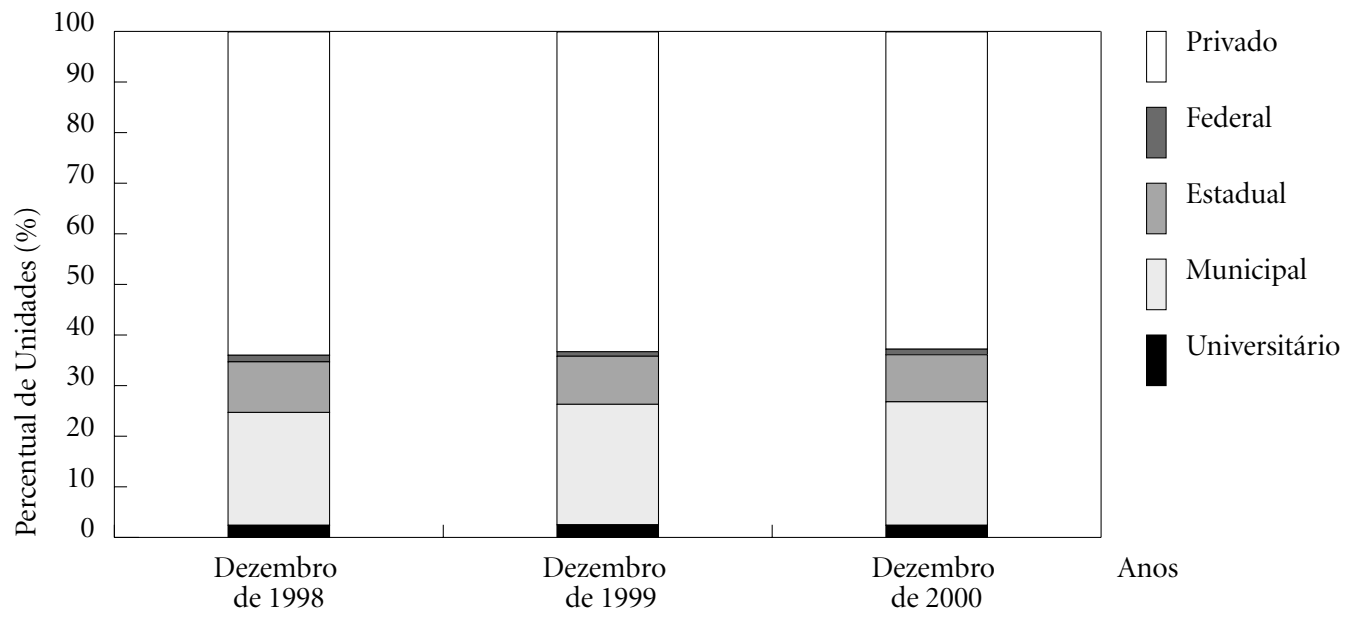

Fonte: DATASUS/MS 
Figura 7

Capacidade instalada ambulatorial por região segundo tipo de prestador dezembro de 2000

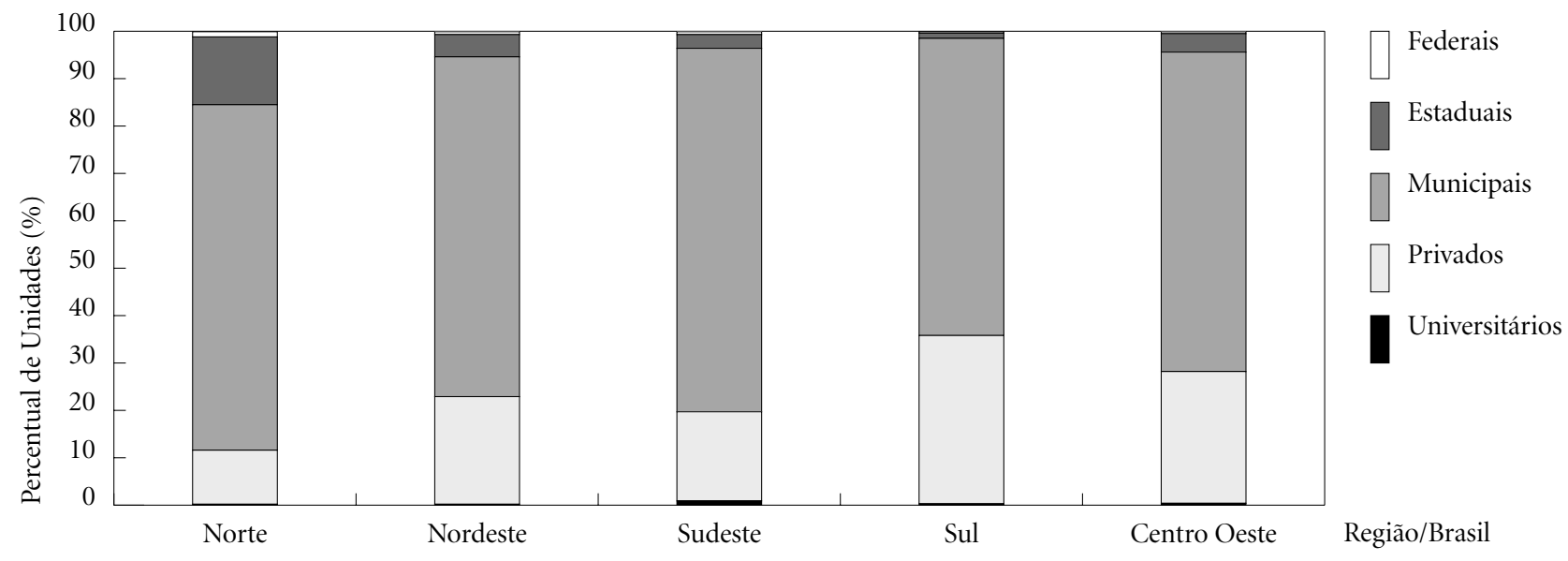

Fonte: DATASUS/MS

cebiam recursos "fundo a fundo", representando cerca de $61 \%$ do total de recursos federais para custeio da assistência.

Quanto aos programas remodeladores da assistência (Programa Agentes Comunitários de Saúde - Pacs/Programa Saúde da Família - PSF), o Piso da Atenção Básica (PAB) e a NOB/96 proporcionaram-lhe notável expansão: de 1994 a 1998, o percentual da população coberta pelo PSF passa de $0.8 \%$ para 7\%, atingindo, de 1998 a 2000, 22,5\%. O binômio PAB fixo/variável, apesar da inexpressividade dos valores médios nacionais de transferência - cerca de R $\$ 16,15$ (dezesseis reais e quinze centavos) para o PAB total -, representa a descentralização dos recursos, homogeneizando a presença da esfera federal e impulsionando a reorganização da atenção básica.

$\mathrm{O}$ incentivo ao aprendizado institucional, implícito nas modalidades de habilitação gradativa - incipiente/parcial/semiplena, na NOB/93 e Gestão Plena da Atenção Básica e de Sistema Municipal, na NOB/96 -, constitui outro importante instrumento para a melhoria da qualidade da gestão pública. Como comprovam estudos recentes, o município que passou por vários tipos de habilitação, atingindo as modalidades mais qualificadas (como a semiplena na NOB/93 e plena na NOB/96), apresenta melhores condições institucionais e administrativas para a gestão pública da saúde. Portanto, o pro- cesso de qualificação e capacitação institucional é essencial à estratégia induzida, isto é, quando o governo central planeja e traça as metas para implementar a descentralização.

\section{Considerações finais}

Pode-se afirmar, no intuito de traçar um balanço do papel dos instrumentos de regulação da descentralização, instituídos através das NOBs e, particularmente, da NOB/96, que esta última, ao ampliar o funcionamento das CIBs (em cada estado) e das Programações Pactuadas Integradas (PPIs), acabou por fortalecer o papel dos estados, entretanto, sem a face da regionalização. Atualmente, mesmo na modalidade mais qualificada prevista pela NOB/96 (Gestão Plena de Sistema Municipal - GPSM), os pactos de gestão - divisão de atribuições entre estados e municípios - propiciaram inúmeros modelos de gestão e gerenciamento que, muitas vezes, são desprovidos de racionalidade sistêmica.

Por essa razão, a atual regulação presente na NOAS tende a destacar o papel da instância estadual no processo de regionalização da assistência à saúde - tanto nos aspectos relativos ao planejamento, programação e controle, como nos investimentos que se façam necessários -, ressaltando a importância de um processo de descentralização da gestão do sistema de saúde 
Figura 8

Capacidade instalada hospitalar por região segundo tipo de prestador

dezembro de 2000

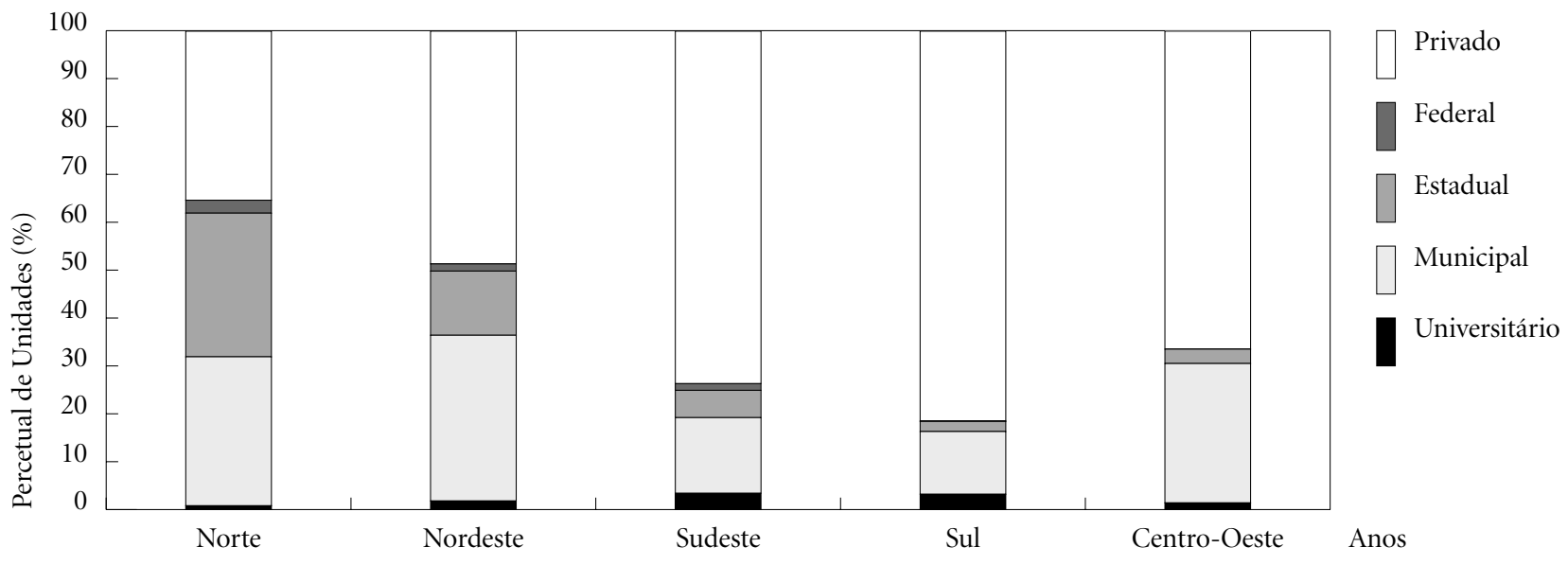

Fonte: DATASUS/MS

para os municípios habilitados em gestão plena, respaldado por uma definição clara de responsabilidades e atrelado à real capacidade de oferta destes municípios.

Entretanto, ao mesmo tempo em que se fortalecem as instâncias estaduais, estas permanecem desprovidas de recursos e incentivos financeiros adequados às suas "novas" funções. Os recursos previstos para o financiamento do SUS continuam vinculados à oferta de serviços, e não se sabe ainda até que ponto os estados poderão superar as suas próprias dificuldades financeiras e administrativas para exercerem seu papel regulador, sem que se sintam compelidos à disputa com os municípios pelos recursos de custeio do sistema.

Cabe ainda questionar se a forte determinação do nível federal sobre os "mínimos assistenciais obrigatórios", principalmente para a configuração dos módulos assistenciais e dos fluxos intermunicipais (previstos pela NOAS), pode ser aplicada de maneira homogênea nas diferentes regiões e estados do país.

Os dados levantados neste artigo sugerem que a complexidade e diversidade do modelo de gestão e gerência do SUS, associadas às fortes desigualdades regionais e ao contexto de relações federativas altamente competitivas e predatórias, podem novamente tensionar a tríade formada por racionalidade sistêmica, financiamento e modelo de atenção.

Finalmente, o modelo de descentralização setorial na saúde, a despeito do esforço permanente do governo central pela indução e regulação do processo, pode ter pouco impacto nos indicadores de oferta e acesso aos serviços, tendo em vista os agudos conflitos de ordem federativa num contexto de restrição fiscal e de infortunada herança de desigualdades econômicas e sociais. 


\section{Referências bibliográficas}

Abrucio FL 1998 Os barões da federação, os governadores e a redemocratização brasileira. Hucitec, São Paulo.

Couto e Silva MMA 1998. O processo de endividamento dos Estados problemas e limites à descentralização e à autonomia. Dissertação de mestrado. Instituto de Economia, Universidade Federal do Rio de Janeiro. 228pp

Costa NR et al. 1999. A descentralização do sistema de saúde no Brasil. Revista do Serviço Público 50(3):33-55

Croisat M 1995. El federalismo en las democracias contemporâneas. Hacer Editorial, Barcelona.

Dente B 1997. Governare in un contesto federale: quali lezioni per la transizione italiana? In Dente B et al. (orgs.). Governare con il federalismo. Edizione Fondazione Giovanni Agnelli, Turim, 1997.
Kugelmas E \& Sola L 1999. Recentralização/descentralização - dinâmica do regime federativo no Brasil dos anos 90. Tempo Social, São Paulo, 11(2):63-83, fevereiro.

Sharpe J 1997. Federalismo e decentralizzazione nel moderno stato democrático. In Dente B. et al. (orgs.). Governare con il federalismo. Edizione Fondazione Giovanni Agnelli, Turim, 1997.

Souza C 2001. Federalismo e gasto social no Brasil: Tensões e tendências. Lua Nova, São Paulo, 52:5-28.

Souza C 1998. Intermediação de interesses regionais no Brasil: o impacto do federalismo e da descentralização. Dados-Revista de Ciências Sociais 42(2):593-634.

Artigo apresentado em 15/4/2002

Versão final apresentada em 1@/7/2002

Aprovado em 29/7/2002 